\begin{tabular}{|} 
Ambiente \& Água - An Interdisciplinary Journal of Applied Science \\
ISSN 1980-993X - doi:10.4136/1980-993X \\
www.ambi-agua.net \\
E-mail: ambi.agua@gmail.com
\end{tabular}

\title{
Qualidade da água de três locais com potenciais fontes de contaminação no Rio Taquari, RS
}

\author{
doi:10.4136/ambi-agua.1789 \\ Received: 21 Oct. 2015; Accepted: 16 Nov. 2015 \\ Thais Muller; Camille Eichelberger Granada; Raul Antonio Sperotto* \\ Centro Universitário UNIVATES, Lajeado, RS, Brasil \\ Programa de Pós-Graduação em Biotecnologia (PPGBiotec) \\ *Autor correspondente: e-mail: rasperotto@univates.br, \\ thais_muller84@hotmail.com, cegranada@univates.br
}

\section{RESUMO}

O Vale do Taquari apresenta uma grande quantidade de indústrias alimentícias e curtumes, que lançam seus efluentes no Rio Taquari, além de um cemitério em Área de Preservação Permanente, localizado no município de Muçum. Este trabalho teve como objetivo realizar análises físico-químicas e microbiológicas da água do Rio Taquari e comparar pontos à montante e à jusante de três locais considerados potencialmente poluidores. Os locais escolhidos foram um cemitério e um curtume no município de Muçum, e um curtume seguido de um frigorífico de frangos no município de Roca Sales. Foram realizadas análises de $\mathrm{pH}$, turbidez, oxigênio dissolvido $\left(\mathrm{O}_{2}\right)$, nitrogênio total $(\mathrm{N})$ e coliformes termotolerantes. Realizou-se também o isolamento de Escherichia coli seguido de testes de resistência aos antibióticos neomicina, rifampicina, clindamicina e penicilina. As análises físico-químicas realizadas neste estudo mostraram que somente a turbidez, em quatro dos seis pontos analisados, apresentou valores acima do permitido pela legislação para águas de classe I, sendo que estes valores elevados provavelmente têm origem inorgânica. As bactérias isoladas no ponto à jusante do cemitério e à montante e à jusante das indústrias de Roca Sales foram sensíveis à neomicina, rifampicina e clindamicina, e resistentes à penicilina. Pode-se concluir, portanto, que mesmo com a liberação dos poluentes, não existe uma interferência significativa na qualidade da água nos três locais analisados do Rio Taquari.

Palavras-chave: análises físico-químicas, atividades antrópicas, efluentes.

\section{Water quality near three sources of potential contamination of the Taquari River - RS}

\begin{abstract}
The Taquari Valley has several food industries and tanneries which release their effluents into the Taquari River, as well as a cemetery in a Permanent Preservation Area in Muçum town. This study performed physicochemical and microbiological analyses of water from before and after three Taquari River sites considered potentially polluting and compared the results of those samples. The chosen sites were a cemetery and a tannery in Muçum and a tannery next to a poultry processing plant located in Roca Sales. We analyzed $\mathrm{pH}$, turbidity,
\end{abstract}


dissolved oxygen $\left(\mathrm{O}_{2}\right)$, total nitrogen $(\mathrm{N})$ and thermotolerant coliforms. We also isolated Escherichia coli and performed resistance tests to neomycin, rifampicin, clindamycin and penicillin antibiotics. The physicochemical analyses showed that only turbidity, in four out of the six analyzed spots, had values above the established threshold of class I water. These elevated values are probably of inorganic origin. Bacteria isolated from the samples collected after the cemetery and both before and after the Roca Sales industries were sensitive to neomycin, rifampicin and clindamycin, and resistant to penicillin. It can be concluded, therefore, that even the release of the pollutant effluents does not substantially interfere with the water quality of the three analyzed sites.

Keywords: anthropic activities, effluents, physicochemical analysis.

\section{INTRODUÇÃO}

A bacia hidrográfica do sistema Taquari-Antas situa-se na região nordeste do estado do Rio Grande do Sul, abrangendo uma área de $26.428 \mathrm{~km}^{2}$, com aproximadamente $530 \mathrm{~km}$ de extensão (Pimenta et al., 2012). Essa bacia nasce no extremo leste do Planalto dos Campos Gerais e tem suas nascentes nos municípios de Cambará do Sul, Bom Jesus e São José dos Ausentes, sendo em sua parte superior denominado de Rio das Antas; e em sua parte inferior, Rio Taquari. Seus principais afluentes pela margem esquerda são os rios Camisas, Tainhas, Lajeado Grande e São Marcos; e pela margem direita, Quebra-Dentes, Prata, Carreiro, Guaporé, Forqueta e Taquari-Mirim (Becker et al., 2013).

De modo geral, as bacias hidrográficas do Brasil, bem como a bacia Taquari-Antas, vêm sofrendo severas modificações que são geradas, na sua maioria, por atividades antrópicas (Becker et al., 2013), sendo que os escoamentos de esgotos são as vias de contaminação mais significativas (Marques et al., 2012). Guedes et al. (2012) relataram que a utilização desses recursos naturais para despejo das indústrias altera significativamente suas características, e o monitoramento da qualidade da água é um dos principais instrumentos para a gestão de recursos, pois possibilita verificar a dimensão do impacto, com o intuito de determinar estratégias para minimizá-lo.

As indústrias alimentícias ou que processam produtos animais como laticínios, frigoríficos e curtumes, são as principais fontes poluidoras. Essas indústrias, além de liberarem diversos poluentes, lançam também vários micro-organismos no ambiente (Iafigliola et al., 2000). Segundo Krewer et al. (2012), esses micro-organismos podem ser resistentes a diversos tipos de antibióticos, sendo que essa resistência pode ser atribuída ao uso de antimicrobianos, desinfetantes e suplementos alimentares utilizados nos processos de produção.

Os curtumes processam as peles de animais para que estas possam ser utilizadas na fabricação de diversos artigos de consumo. Nesse processamento, são utilizados produtos altamente tóxicos como sulfato de cromo, álcalis à base de mercúrio, sulfeto de sódio, cloreto de sódio, fungicida e óleo catiônico (Cunha e Shiraiwa, 2011). O processo com cromo, utilizado por cerca de $90 \%$ dessas indústrias, gera resíduos que necessitam de tratamento adequado, pois podem interferir significativamente no ambiente onde são liberados (Oliveira et al., 2008).

Os cemitérios, muitas vezes localizados em locais inadequados, também causam impacto devido à geração e percolação pelo solo de um líquido escuro chamado necrochorume. Esse líquido é resultado da decomposição dos corpos e contem substâncias orgânicas, inorgânicas e micro-organismos, podendo contaminar o solo e os recursos hídricos localizados nas proximidades (Silva e Malagutti Filho, 2010). A contaminação do meio ocorre principalmente no primeiro ano do sepultamento. O necrochorume é mais denso que a água, rico em sais 
minerais e pode conter ainda resíduos de tratamentos químicos hospitalares, como quimioterápicos, formaldeído e metanol, além de patógenos associados a mortes por doenças infectocontagiosas e óxidos metálicos como $\mathrm{Ti}, \mathrm{Cr}, \mathrm{Cd}, \mathrm{Pb}, \mathrm{Fe}, \mathrm{Mn}, \mathrm{Ni}$, que podem ser lixiviados dos adereços das urnas (Silva et al., 2009). A Resolução no 335 do CONAMA, de 3 de abril de 2003 (CONAMA, 2003), dispõe sobre o licenciamento ambiental de cemitérios e estabelece que os mesmos são considerados importantes fontes de contaminação, sendo que sua implantação necessita estar dentro dos critérios legais de proteção ambiental para proteger o solo e as águas subterrâneas.

Para obter uma estimativa da contaminação existente nas bacias hidrográficas, destino do despejo de indústrias como as citadas anteriormente, e também por contaminantes em suas margens, como é o caso do cemitério, é necessária a realização de análises que avaliem aspectos físicos, químicos e microbiológicos (Castro, 2006). Com base nos valores obtidos nessas análises é possível se verificar se os corpos hídricos encontram-se de acordo com o uso ao qual eles se destinam. A Resolução 357/05 do CONAMA (2005) estabelece os parâmetros físicos, químicos e microbiológicos para a classificação dessas águas. Essa resolução admite cinco classes: especial, I, II, III e IV, sendo que a classe especial pode ser utilizada para consumo humano apenas com desinfecção, enquanto que as classes I, II e III necessitam de tratamento simplificado, convencional e avançado, respectivamente. Os rios classificados nas quatro classes também são destinados à preservação dos ambientes aquáticos, à manutenção do equilíbrio natural das comunidades aquáticas, à irrigação, à recreação, à aquicultura, à pesca e à dessedentação de animais. Os rios de classe IV servem apenas para a navegação e harmonia paisagística.

O Rio Taquari serve como despejo final de efluentes das indústrias de couros, suínos e frangos da região do Vale do Taquari. Este mesmo rio é muito utilizado pela população para atividades de lazer. Devido a isso, é necessário um rigoroso controle de sua qualidade, assegurando boas condições sanitárias em sua utilização, bem como garantindo a sobrevivência da biota local. Assim, este trabalho teve como objetivo realizar análises físico-químicas e microbiológicas da água do Rio Taquari e comparar pontos à montante e à jusante de três locais considerados potencialmente poluidores. Os locais escolhidos foram um cemitério e um curtume no município de Muçum, e uma indústria de frangos seguida de um curtume no município de Roca Sales. Foram feitas análises de coliformes termotolerantes, $\mathrm{pH}$, nitrogênio total $(\mathrm{N})$, oxigênio dissolvido $\left(\mathrm{O}_{2}\right)$ e turbidez. Realizou-se também o isolamento de Escherichia coli seguido de teste de resistência aos antibióticos neomicina, rifampicina, clindamicina e penicilina.

\section{MATERIAL E MÉTODOS}

\subsection{Pontos amostrados e coleta de material}

Os pontos de coleta estão localizados na Bacia Taquari-Antas, mais precisamente na sua parte inferior, onde este se denomina Rio Taquari. A ocupação e o uso do solo, ao longo da referida bacia, são intensamente diversificados, apresentando municípios densamente povoados ou ainda aqueles onde a agricultura e a indústria são a principal atividade econômica. Além disso, alguns municípios concentram ambas as características. Conforme visto na Figura 1, os pontos avaliados estão compreendidos entre os municípios de Muçum e Roca Sales, sendo um cemitério e um curtume em Muçum e um curtume seguido de uma indústria de frangos no município de Roca Sales. Os pontos ficam em torno de cinquenta metros antes e após o local de despejo dos efluentes e foram denominados da seguinte forma: Local 1, abrangendo os Pontos 1 e $2(\mathrm{P} 1$ e $\mathrm{P} 2)$, respectivamente à montante e à jusante do cemitério em Muçum; Local 2, abrangendo os Pontos 3 e 4 (P3 e P4), respectivamente à 
montante e à jusante do curtume existente no município de Muçum; e Local 3, abrangendo os Pontos 5 e 6 (P5 e P6), respectivamente à montante e à jusante do curtume seguido de uma indústria de frangos existentes no município de Roca Sales. As coordenadas geográficas dos

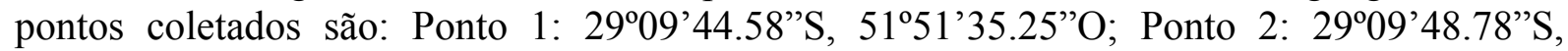

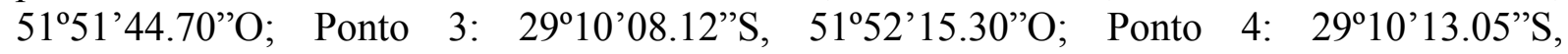

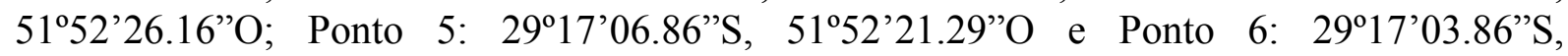
51 ${ }^{\circ} 52^{\prime} 34.65$ "O. As coletas (1 L para cada amostra) ocorreram nos meses de julho à novembro de 2013 e foram realizadas em triplicatas biológicas (totalizando 18 amostras por dia de coleta) e em triplicata experimental (coleta em três dias diferentes).

\subsection{Análises de coliformes termotolerantes}

As análises de coliformes termotolerantes procederam-se com base na metodologia da Instrução Normativa $n^{\circ} 62$ do Ministério da Agricultura, Pecuária e Abastecimento (MAPA), pela técnica do Número Mais Provável (NMP). Foram dispensados $10 \mathrm{~mL}$ da amostra em uma série de três tubos contendo meio Lauryl Sulfato de Sódio $\left(\right.$ OXOID $\left.^{\circledR}\right)$ com tubos de Durham, em concentração dupla, e $1 \mathrm{~mL}$ da amostra em uma série de três tubos contendo meio Lauryl Sulfato de Sódio $\left(\right.$ OXOID $\left.^{\circledR}\right)$ com Durham, em concentração simples. Efetuaram-se ainda duas diluições da amostra. Os tubos foram incubados a $36^{\circ} \mathrm{C}$ por no máximo 48 hs. Transcorrido este período, os tubos positivos (que apresentaram formação de gás dentro do Durham ou leve efervescência sob fraca agitação) foram inoculados para os tubos contendo meio Verde Brilhante bile $2 \%\left(\right.$ OXOID $\left.^{\circledR}\right)$ com Durham, e incubados a $36^{\circ} \mathrm{C}$ por 24 hs. Após esse período, os tubos positivos foram inoculados para tubos de caldo EC Medium (Acumedia ${ }^{\circledR}$ ) com Durham e incubados por no máximo 48 hs. Para cada caldo, anotou-se o número de tubos positivos. A partir da combinação de números correspondentes aos tubos que apresentaram resultado positivo, é verificado o número mais provável (NMP) de acordo com a tabela correspondente (MAPA), onde o resultado é expresso em NMP 100 $\mathrm{mL}^{-1}$.

\subsection{Análises físico-químicas}

Os aspectos físico-químicos como $\mathrm{pH}$, nitrogênio total $(\mathrm{N})$, oxigênio dissolvido $\left(\mathrm{O}_{2}\right)$ e turbidez foram analisados, respectivamente, utilizando-se os equipamentos: pHmetro (Digimed DM-20), TNM1 Schimadzu Total Nitrogen Measuring unit, medidor de Oxigênio Dissolvido portátil Digimed DM-4P e Turbidímetro Digimed DM-TU.

\subsection{Isolamento de Escherichia coli e teste de resistência aos antibióticos}

$\mathrm{O}$ isolamento de E. coli foi realizado segundo a metodologia descrita por Borges et al. (2003). A amostra foi diluída e inoculada em placas contendo ágar Mac Conkey (MC) $\left(\mathrm{OXOID}^{\circledR}\right.$ ) e incubadas a $37^{\circ} \mathrm{C}$ por 18 a 24 hs. As colônias lactose positivas (coloração rosa forte) foram inoculadas em ágar Eosin Methylene Blue (EMB) (OXOID ${ }^{\circledR}$ ). As colônias típicas de E. coli (escuras com brilho verde-metálico) foram preservadas em ágar Trypticase Soy Agar (TSA) $\left(\right.$ OXOID $\left.^{\circledR}\right)$ inclinado. No teste de resistência a antibióticos, cada isolado bacteriano preservado em ágar TSA foi inoculado em caldo Brain Heart Infusion (BHI) $\left(\mathrm{OXOID}^{\circledR}\right)$ por $24 \mathrm{hs}$ a $36^{\circ} \mathrm{C}$, e transferidos para placas de ágar Mueller Hinton $\left(\mathrm{BD}^{\mathbb{R}}\right)$, de acordo com os métodos descritos por Correa et al. (2005). Os antibióticos testados foram Neomicina (30 $\mu \mathrm{g})$, Rifampicina (5 $\mu \mathrm{g})$, Clindamicina (2 $\mu \mathrm{g})$ e Penicilina (G100).

\subsection{Análises estatísticas}

Os dados obtidos nas análises das amostras nos pontos à montante e à jusante foram comparados pelo teste $t$ de Student $(\mathrm{p} \leq 0,01)$ para determinar se os pontos de descarte de efluentes analisados modificam a qualidade das águas do Rio Taquari. Os três locais à 
motante foram comparados entre si usando-se One-Way ANOVA seguido de teste de Tukey $(\mathrm{p} \leq 0,05)$. O mesmo foi feito com os três locais à jusante do descarte. Os resultados também foram comparados com os parâmetros da Resolução 357/05 do CONAMA, de 17 de março de 2005, que dispõe sobre a classificação dos corpos de água e diretrizes ambientais para o seu enquadramento, bem como estabelece as condições e padrões de lançamento de efluentes.

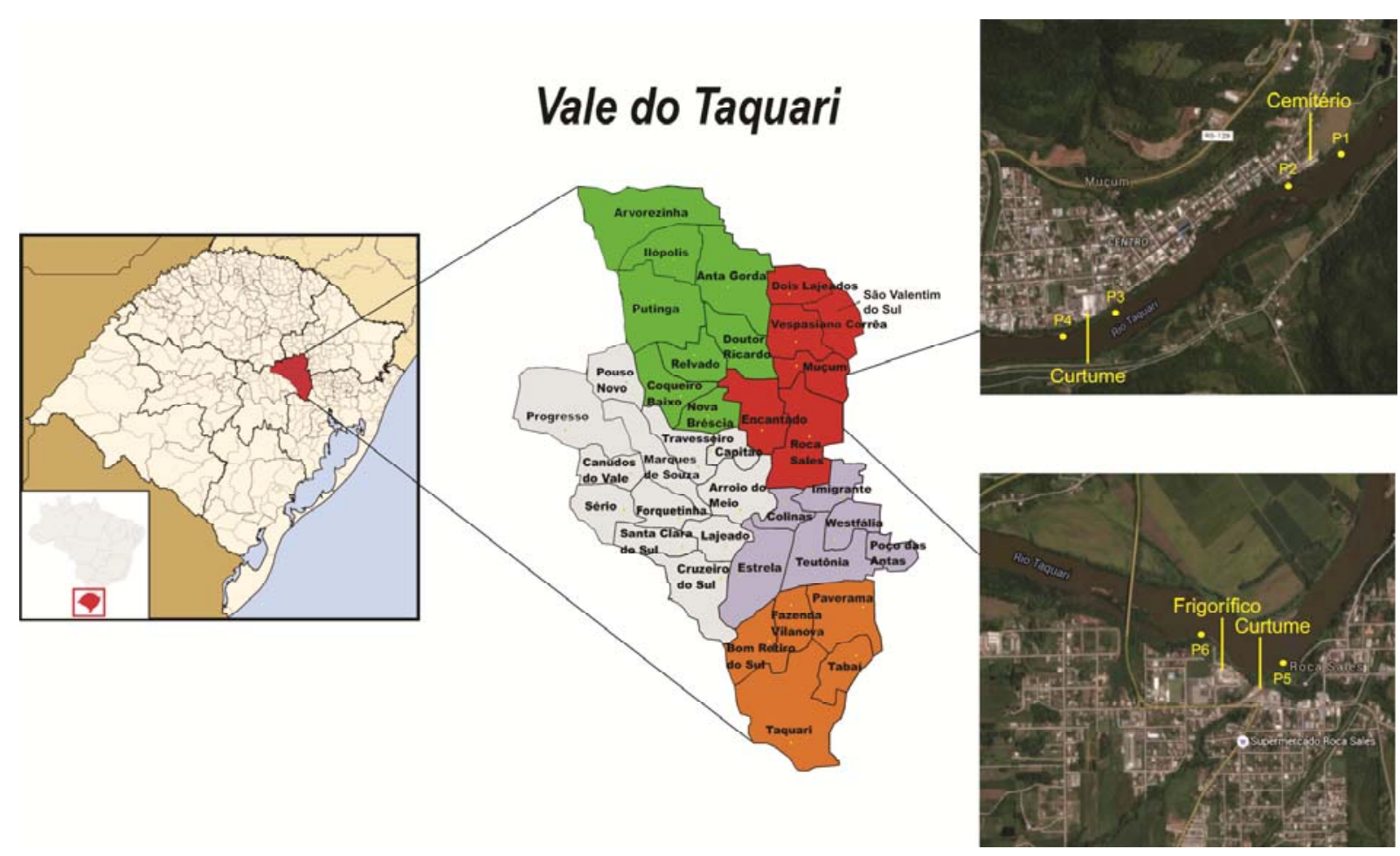

Figura 1. Locais de coleta na Bacia Taquari-Antas. Local 1, abrangendo os Pontos 1 e 2 (P1 e P2), respectivamente à montante e à jusante do cemitério em Muçum; Local 2, abrangendo os Pontos 3 e 4 (P3 e P4), respectivamente à montante e à jusante do curtume existente no município de Muçum; e Local 3, abrangendo os Pontos 5 e 6 ( $\mathrm{P} 5$ e P6), respectivamente à montante e à jusante do curtume seguido de uma indústria de frangos existentes no município de Roca Sales.

\section{RESULTADOS E DISCUSSÃO}

A Figura 2 mostra as análises físico-químicas e microbiológicas realizadas neste trabalho. A temperatura da água durante a análise de $\mathrm{pH}$ ficou entre 8 e $12^{\circ} \mathrm{C}$ em todas as amostras. De acordo com a Figura $2 \mathrm{a}$, as análises de $\mathrm{pH}$ não apresentaram diferenças entre os pontos à montante e à jusante de nenhum dos três locais analisados, sendo que os valores de $\mathrm{pH}$ ficaram próximos da neutralidade em todas as amostras coletadas. Quando comparadas entre si, as amostras dos pontos à montante não apresentaram diferenças. Nas amostras dos pontos à jusante, o ponto 2, localizado após o cemitério do município de Muçum, teve um valor maior que o ponto 6, localizado após as indústrias de Roca Sales. O fato de não haver diferenças entre os pontos à montante e à jusante pode ser explicado pela correção de $\mathrm{pH}$ feita nos efluentes antes de serem despejados nos corpos d'água (Ferreira Filho e Hang Chui, 2006). Cabe salientar que não ocorreu diferença estatística nem mesmo no local 1 (cemitério), onde o resíduo não sofre nenhum tratamento. A Resolução CONAMA 357/05 estabelece que, para as águas de Classe Especial, I e II, que são destinadas à preservação da vida aquática, a faixa de $\mathrm{pH}$ deve ser de 6,0 à 9,0 , sendo que o $\mathrm{pH}$ encontrado em todos os locais foi 
considerado propício à biota aquática.

A Figura $2 \mathrm{~b}$ mostra os resultados das análises de turbidez. Neste parâmetro foram observadas diferenças significativas entre os pontos à montante e à jusante em dois dos três locais avaliados. No cemitério (Local 1) e no curtume do município de Muçum (Local 2), a turbidez foi maior nos pontos à montante do que nos pontos à jusante. Quando comparadas as médias dos pontos à montante e à jusante, podemos constatar que a turbidez do ponto 1 , à montante do cemitério, é menor que dos demais pontos à montante, e a média da turbidez do ponto à jusante das indústrias de Roca Sales (Local 3) é maior que os demais pontos à jusante. A turbidez mais elevada pode estar associada a níveis mais altos de matéria orgânica ou inorgânica, como por exemplo, sólidos suspensos, devido a diversos fatores como o tipo de solo, uso do solo nas margens, temperatura e níveis de pluviosidade (Silva et al., 2008). A alteração na turbidez causa transtornos à biota aquática do rio, podendo interferir na fotossíntese e gerar um problema na cadeia alimentar, além de ser prejudicial a algumas espécies de peixes (Wilson, 2010). Segundo a Resolução 357/05, os valores para a turbidez considerados aceitos são de até 40 UNT para os rios de classe I, e 100 UNT para os rios de classe II. Somente os pontos 2 e 4 (à jusante do cemitério e à jusante do curtume de Muçum) apresentaram resultados inferiores a $40 \mathrm{UNT}$, ficando dentro do limite estabelecido para água de classe I. O ponto 1 (à montante do cemitério) apresentou 45,23 UNT, sendo enquadrada como água de classe II. Entretanto, os demais pontos (3, 5 e 6) ficaram acima de 100 UNT, e dessa forma poderiam ser utilizados somente para os usos aos quais as águas de classes III e IV se prestam, ressaltando que essas duas classes não possuem limites estabelecidos para a turbidez.

A Figura 2c mostra que as análises do $\mathrm{O}_{2}$ dissolvido não apresentaram alterações significativas entre os pontos à montante e à jusante dos três locais de coleta. No ponto à montante do cemitério (Local 1), foi verificado um valor menor que nos outros pontos à montante analisados (o curtume de Muçum e as indústrias de Roca Sales). O mesmo ocorre com o ponto à jusante do cemitério (P2), que apresenta menores valores que os outros dois pontos à jusante (P4 e P6). A Resolução 357/05 do CONAMA estabelece que para a preservação da vida aquática, o nível mínimo de $\mathrm{O}_{2}$ dissolvido para águas de classe I é de 6,0 $\mathrm{mg} \mathrm{L}^{-1}$, e de classe II é 5,0 $\mathrm{mg} \mathrm{L}^{-1}$. Os níveis encontrados nas nossas análises variaram de 8,21 $\mathrm{mg} \mathrm{L}^{-1}$ a $9,03 \mathrm{mg} \mathrm{L}^{-1}$, ficando dentro do limite estabelecido pela legislação para águas de classes I e II. A quantidade de $\mathrm{O}_{2}$ dissolvido nos corpos d'água é um dos indicadores mais importantes da qualidade dessa água. Levando em conta que um bom nível de $\mathrm{O}_{2}$ é de extrema importância para a respiração aeróbica dos organismos do rio em questão (Janzen et al., 2008), pode-se dizer que o Rio Taquari possui um ambiente propício aos organismos que o habitam em todos os seis pontos analisados.

As análises de $\mathrm{N}$ total mostraram diferenças entre os pontos à montante e à jusante dos três locais analisados (Figura 2d). Ocorreu um aumento significativo nos valores de $\mathrm{N}$ total em todos os pontos posteriores ao descarte dos efluentes (P2, P4 e P6). O Local 3 (curtume e indústria de frangos de Roca Sales), à montante e à jusante do despejo, apresentou os maiores níveis de $\mathrm{N}$ total. $\mathrm{O}$ Local 1 (cemitério) apresentou o menor nível de $\mathrm{N}$ em seu ponto posterior, quando comparado com os pontos posteriores dos locais 2 e 3 . $\mathrm{O} \mathrm{N}$ é um composto que promove o crescimento dos organismos e a eutrofização, que resulta na diminuição do $\mathrm{O}_{2}$ dissolvido e causa problemas à biota aquática (Timofiecsyk et al., 2012). O aumento do $\mathrm{N}$ total nos pontos à jusante pode estar relacionado aos efluentes despejados nesses locais. Estes efluentes são ricos em matéria orgânica e, quando não tratados de forma adequada, apresentam grande quantidade de $\mathrm{N}$ (Nunes et al., 2011). Cabe ressaltar que, apesar de ter ocorrido um aumento significativo nos pontos posteriores, todos os pontos possuem níveis 
de $\mathrm{N}$ total que variam de $0,52 \mathrm{mg} \mathrm{L}^{-1}$ a $1,12 \mathrm{mg} \mathrm{L}^{-1}$, ou seja, dentro do estabelecido pela legislação vigente (até $2,18 \mathrm{mg} \mathrm{L}^{-1}$ para águas de classes I e II em ambientes lóticos). Exceto para o local 3, o valor mais elevado nas análises de $\mathrm{N}$ dos pontos à jusante está em desacordo com o que foi observado para a turbidez, que foi maior nos pontos à montante dos locais $1 \mathrm{e} 2$ (cemitério e curtume de Muçum). A turbidez maior nesses pontos provavelmente seja devido à presença de compostos inorgânicos, por exemplo, sólidos suspensos (Wilson, 2010), que podem ser ressuspendidos do fundo por algum processo físico decorrente da geomorfologia do rio. Entretanto, mais estudos seriam necessários, em cada um dos locais analisados, para se chegar a uma conclusão.

Nas análises microbiológicas (Figura 2e), não houve diferença significativa entre os pontos à montante e à jusante de nenhum dos três locais avaliados. Quando os pontos à jusante foram comparados entre si, foi visto que o ponto 1 (cemitério) possui uma média maior que os pontos à jusante dos locais 2 e 3 (curtume e indústrias de Roca Sales). No cemitério (Local 1), os valores médios da contagem de coliformes das amostras à montante $\mathrm{e}$ à jusante ficaram em torno de $20 \mathrm{NMP} 100 \mathrm{~mL}^{-1}$. Tendo em vista que esse parâmetro pode estar relacionado à quantidade de matéria orgânica de origem fecal e é um indicativo da qualidade da água (Skorczewski et al., 2012), pode-se concluir que há uma quantidade maior de coliformes no ponto à jusante do cemitério, quando comparado aos demais pontos à jusante, e isso pode estar associado ao escoamento do necrochorume. Silva et al. (2009) ressaltou que o necrochorume liberado na decomposição dos cadáveres possui elevada quantidade de material orgânico, assim como uma alta concentração de micro-organismos, oriundos principalmente dos corpos que ainda não estão completamente decompostos. Cabe ressaltar que nas análises de $\mathrm{O}_{2}$ dissolvido, o ponto à jusante do cemitério apresentou um nível menor que os pontos à jusante do curtume e das indústrias de Roca Sales, reforçando a hipótese que esse ponto possui maior contaminação.

As amostras foram submetidas também ao isolamento de Escherichia coli seguido de testes de resistência a antibióticos. Não foram obtidas cepas no ponto à montante do cemitério (P1) e nos pontos à montante e à jusante do curtume de Muçum (P3 e $\mathrm{P} 4$, respectivamente). No ponto à jusante do cemitério (P2), obteve-se uma maior quantidade de cepas, indicando que existe uma grande quantidade desses micro-organismos no local. Este resultado é reforçado pelas análises dos coliformes termotolerantes e de $\mathrm{O}_{2}$ dissolvido. $\mathrm{O}$ fato de não isolarmos cepas nos pontos à montante do cemitério e do curtume de Muçum (P1 e P3, respectivamente), reforça a ideia de que a turbidez alterada nesses pontos seja de origem inorgânica. Nos pontos à montante e à jusante das indústrias de Roca Sales (P5 e P6, respectivamente), a quantidade de cepas isoladas foi a mesma. Nos testes com os antibiogramas, os três pontos ( $\mathrm{P} 2, \mathrm{P} 5$ e P6) mostraram sensibilidade à Neomicina e à Rifampicina. O crescimento de uma das cepas isoladas do ponto 2 foi retardado pela Clindamicina. Todas as cepas isoladas demonstraram resistência à penicilina. Segundo Dias et al. (2010), a E. coli é um micro-organismo resistente aos principais antibióticos, e é capaz de produzir $\beta$-lactamase, uma enzima que rompe os anéis $\beta$-lactâmicos e inativa as penicilinas.

Quando os valores obtidos nas análises são comparados com os parâmetros da legislação vigente, percebe-se que o Rio Taquari não pode ser enquadrado como um rio de classe I em todos os trechos analisados. Os valores obtidos nas análises de $\mathrm{pH}, \mathrm{O}_{2}$ dissolvido, $\mathrm{N}$ total e coliformes termotolerantes ficaram dentro dos padrões estabelecidos para a classe I em todas as amostras analisadas. Entretanto, as análises de turbidez de quatro dos seis pontos analisados (P1, P3, P5 e P6) apresentaram valores acima do máximo permitido para águas de classe I (40 UNT), sendo que em três desses pontos (P3, P5 e P6) os valores ficaram acima do máximo permitido para águas de classe II (100 UNT). 
A.

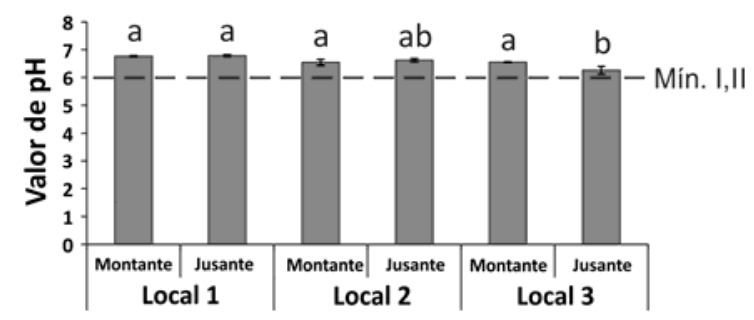

C.

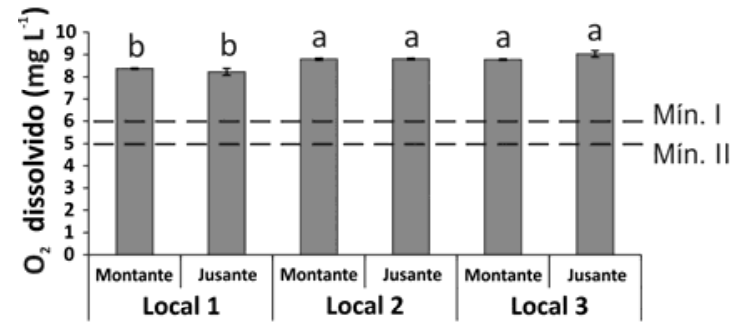

B.

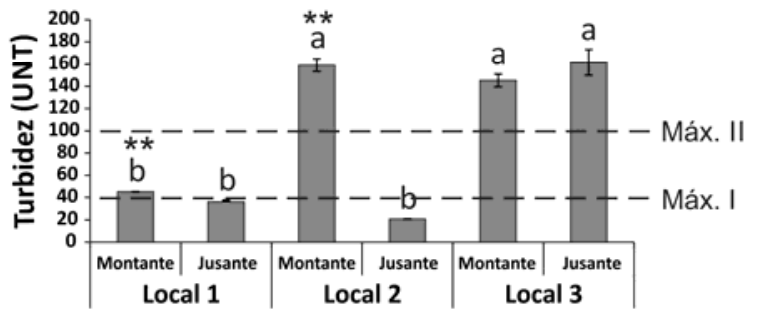

D.

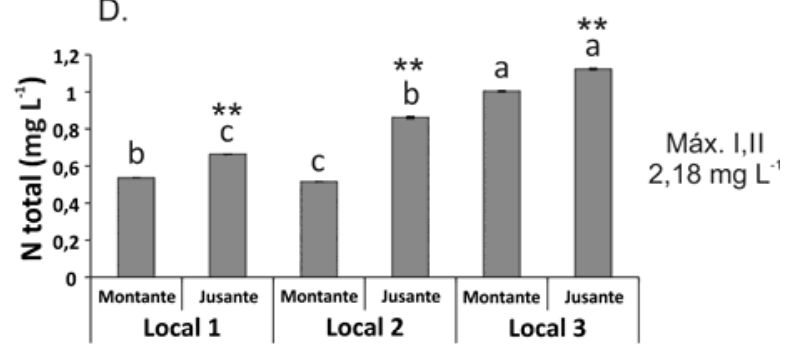

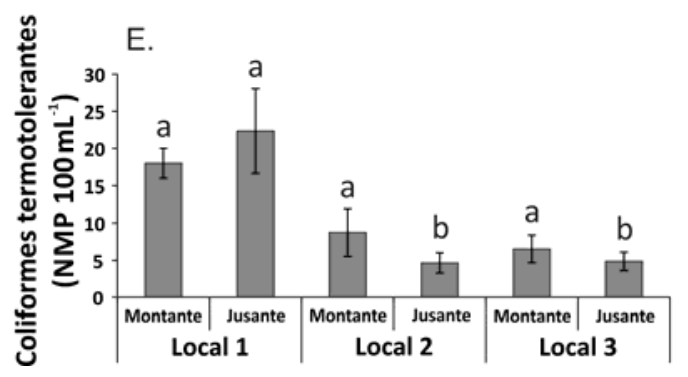

Figura 2. Análises físico-químicas e microbiológicas. (a) $\mathrm{pH}$; (b) Turbidez; (c) $\mathrm{O}_{2}$ dissolvido; (d) $\mathrm{N}$ total; (e) Coliformes Termotolerantes. Os locais 1, 2 e 3 correspondem, respectivamente, ao cemitério do município de Muçum, ao curtume do município de Muçum e às indústrias de frangos e de couros no município de Roca Sales. Os dados são mostrados como média \pm erro padrão. As análises estatísticas referem-se à comparação "à montante" X "à jusante" em cada um dos locais (teste $t$ de Student, $\mathrm{p} \leq 0,01$, mostrado por dois asteriscos), e à comparação, separadamente, dos três locais "à montante" e dos três locais "à jusante" (One-Way ANOVA, seguido de teste de Tukey, $p \leq 0,05$, mostrado por letras nas colunas). Máx. = Valor máximo permitido pela legislação vigente; Mín. = Valor mínimo permitido pela legislação vigente. UNT = Unidades Nefelométricas de Turbidez.

\section{CONCLUSÃO}

Com este estudo podemos concluir que, mesmo tendo uma intensa atividade antropogênica em suas margens, o Rio Taquari não apresenta índices de poluição alarmantes, podendo ser classificado como água de classe I de acordo com a maioria dos parâmetros analisados, exceto turbidez, cuja origem é provavelmente inorgânica. No momento não temos como afirmar o verdadeiro motivo da alta turbidez em alguns pontos, somente podemos especular que diferentes níveis de precipitação ou diferentes usos do solo nas margens poderiam afetar a turbidez desses pontos. Mesmo tendo um cemitério em atividade em sua margem e sendo o local de despejo dos efluentes de diversas indústrias do Vale do Taquari, os trechos analisados deste rio possuem águas com baixo nível de contaminação e, ao que tudo indica, o tratamento de efluentes utilizados pelas indústrias de couros e frangos entre os municípios de Muçum e Roca Sales é eficaz. 


\section{REFERÊNCIAS}

BECKER, F. G.; DE FRIES, L. C. C.; FERRER, J.; BERTACO, V. A.; LUZ-AGOSTINHO, K. D. G.; SILVA, J. F. P. et al. Fishes of the Taquari-Antas river basin (Patos Lagoon basin), southern Brazil. Brazilian Journal of Biology, v. 73, p. 79-90, 2013. http://dx.doi.org/10.1590/S1519-69842013000100010

BORGES, L. G. A.; DALLA VECHIA, V.; CORÇÃO, G. Characterization and genetic diversity via REP-PCR of Escherichia coli isolates from polluted waters in southern Brazil. FEMS Microbiology Ecology, v. 45, p. 173-180, 2003. http://dx.doi.org/10.1016/S0168-6496(03)00147-8

CASTRO, V. G. Utilização da água na indústria de alimentos. 2006. 45f. Monografia (Especialização em Higiene e Inspeção de Produtos de Origem Animal e Vigilância Sanitária) - Universidade Castelo Branco, São Paulo, 2006.

CONSELHO NACIONAL DO MEIO AMBIENTE - CONAMA. Resolução n 335 , de 3 de abril de 2003. Dispõe sobre o licenciamento ambiental de cemitérios. Diário Oficial [da] União, Brasília, n. 101, 28 maio 2003, p. 98-99.

CONSELHO NACIONAL DO MEIO AMBIENTE - CONAMA. Resolução nº 357, de 17 de março de 2005. Dispõe sobre a classificação dos corpos de água e diretrizes ambientais para o seu enquadramento, bem como estabelece as condições e padrões de lançamento de efluentes, e dá outras providências. Diário Oficial [da] União, Brasília, n. 53, 18 mar. 2005, p. 58-63.

CORREA, A. A.; FUENTEFRIA, D. B.; CORÇÃO, G. Antimicrobial resistance analysis among enterococci isolated from pig feces. Acta Scientiae Veterinarie, v. 33, p.155$159,2005$.

CUNHA, L. J.; SHIRAIWA, S. Aplicação do método eletromagnético indutivo na investigação da pluma de contaminação da água subterrânea por resíduos de cromo de curtume. Revista Brasileira de Geofísica, v. 29, p. 127-134, 2011. http://dx.doi.org/10.1590/S0102-261X2011000100009

DIAS, M. T.; SANTOS, P. C. R. F.; OLIVEIRA, L. A. T.; MARIN, V. A. Evaluation of antimicrobial sensitivity of Escherichia coli strains isolated from mussels (Perna perna L.). Ciência \& Tecnologia de Alimentos, v. 30, p. 319-324, 2010.

FERREIRA FILHO, E.; HANG CHUI, Q. S. Quality of measurements and neutralization of alkaline effluents with carbon dioxide. Engenharia Sanitária e Ambiental, v. 11, p. 169-174, 2006. http://dx.doi.org/10.1590/S1413-41522006000200010

GUEDES, H. A. S.; DEMETRIUS D. S.; ABRAHÃO A. A. E.; CELSO B. M. R.; ANTONIO T. M.; JOSÉ H. P. S. Application of multivariate statistical analysis in the study of water quality in the Pomba River (MG). Revista Brasileira de Engenharia Agrícola e Ambiental, v. 16, p. 558-563, 2012. http://dx.doi.org/10.1590/S141543662012000500012

IAFIGLIOLA, M. C.; MENTEN, J. F. M.; RACANICCI, A. M. C.; GAIOTTO, J. B. Copper and antibiotic as growth promoters in rations for broiler chickens. Revista Brasileira de Ciência Avícola, v. 2, p. 201-208, 2000. http://dx.doi.org/10.1590/S1516635X2000000300002 
JANZEN, J. G.; SCHULZ, H. E.; LAMON, A. W. Measurements of dissolved oxygen concentration at water surface. Engenharia Sanitária e Ambiental, v. 13, p. 278-283, 2008. http://dx.doi.org/10.1590/S1413-41522008000300006

KREWER, C. C.; GRESSLER, L. T.; COSTA, M. M.; KREWER, C. C.; VARGAS, A. C. Susceptibility to disinfectants and antimicrobial resistance profile in Escherichia coli isolates. Pesquisa Veterinária Brasileira, v. 32, p. 1116-1120, 2012. http://dx.doi.org/10.1590/S0100-736X2012001100007

MARQUES, R. F. P. V.; SILVA, A. M.; RODRIGUES, L. S.; COELHO, G. Impacts of urban solid waste disposal on the quality of surface water in three cities of Minas Gerais Brazil. Ciência e Agrotecnologia, v. 36, p. 684-692, 2012. http://dx.doi.org/10.1590/S1413-70542012000600010

NUNES, M. A. G.; KUNZ, A.; STEINMETZ, R. L. R.; PANIZ, J. N. G. Application of swine culture treated effluent for swine manure dilution and nitrogen removal by denitrification. Engenharia Agrícola, v. 31, p. 388-398, 2011. http://dx.doi.org/10.1590/S0100-69162011000200019

OLIVEIRA, D. Q. L.; CARVALHO, K. T. G.; BASTOS, A. R. R.; OLIVEIRA, L. C. A.; MARQUES, J. J. G. S. M.; NASCIMENTO, R. S. M. P. Use of leather industry residues as nitrogen sources for elephantgrass. Revista Brasileira de Ciências do Solo, v. 32, p. 417-424, 2008. http://dx.doi.org/10.1590/S0100-06832008000100039

PIMENTA, A. M; FURLANETTO, L. M.; ALBERTONI, E. F.; PALMA-SILVA, C. Water quality in the lotic area of the Antas river before and after the construction of the Monte Claro hydroelectric plant, south Brazil. Acta Limnologica Brasileira, v. 24, p. 314325, 2012. http://dx.doi.org/10.1590/S2179-975X2013005000001

SILVA, A. E. P.; ANGELIS, C. F.; MACHADO, L. A. T.; WAICHAMAN, A. V. Impacts of precipitation on the water quality of the Purus River. Acta Amazonica, v. 38, p. 733742, 2008. http://dx.doi.org/10.1590/S0044-59672008000400017

SILVA, R. W. C.; MALAGUTTI FILHO, W. Application of electrical imaging in the study of contamination from cemeteries. Geociências, v. 29, p. 343-354, 2010.

SILVA, R. W. C.; MALAGUTTI FILHO, W.; MOREIRA, C. A. Emprego do método da eletrorresistividade no estudo da contaminação subterrânea do cemitério municipal de Vila Rezende, Piracicaba - SP. Revista Brasileira de Geofísica, v. 27, p. 389-399, 2009. http://dx.doi.org/10.1590/S0102-261X2009000300007

SKORCZEWSKI, P. Abundance and distribution of fecal indicator bacteria in recreational beach sand in the southern Baltic Sea. Revista de Biología Marina y Oceanografia, v. 47, p. 503-512, 2012.

TIMOFIECSYK, A.; FAVARETTO, N.; PAULETTI, V.; DIECKOW, J. Carbon and nitrogen losses with liquid catlle manure from a clayey oxissol under no-till and natural rainfall. Revista Brasileira de Ciência do Solo, v. 36, p. 1924-1930, 2012. http://dx.doi.org/10.1590/S0100-06832012000600026

WILSONB, P. C. Water quality notes: water clarity (turbidity, suspended solids, and color). University of Florida, 2010. 